\title{
A pathway approach to investigate the function and regulation of SREBPs
}

\author{
Sabine Daemen • Martina Kutmon • \\ Chris T. Evelo
}

Received: 22 January 2013/ Accepted: 5 March 2013/Published online: 21 March 2013

(c) The Author(s) 2013. This article is published with open access at Springerlink.com

\begin{abstract}
The essential function of sterol regulatory element-binding proteins (SREBPs) in cellular lipid metabolism and homeostasis has been recognized for a long time, and the basic biological pathway involving SREBPs has been well described; however, a rapidly growing number of studies reveal the complex regulation of these SREBP transcription factors at multiple levels. This regulation allows the integration of signals of diverse pathways involving nutrients, contributing to cellular lipid and energy homeostasis. This review attempts to integrate this knowledge. The description of the SREBP pathway is Web-linked as it refers to the online version of the pathway on wikipathways.org, which is interactively linked to genomics databases and literature. This allows a more extensive study of the pathway through reviewing these links.
\end{abstract}

Keywords SREBP $\cdot$ Cholesterol $\cdot$ Lipid metabolism · Signaling pathway $\cdot$ WikiPathways

\section{Introduction}

Sterol regulatory element-binding proteins (SREBPs) play an important role in the regulation of the intracellular cholesterol concentration and in overall lipid homeostasis. Since lipids and cholesterol are important components of cellular membranes and precursors for steroid hormones, bile salts,

S. Daemen · M. Kutmon · C. T. Evelo $(\bowtie)$

Department of Bioinformatics, BiGCaT, Maastricht University,

Maastricht, The Netherlands

e-mail: chris.evelo@maastrichtuniversity.nl

M. Kutmon · C. T. Evelo

Netherlands Consortium for Systems Biology (NCSB),

Amsterdam, The Netherlands and essential signaling molecules, a tight regulation is vital. SREBPs provide a negative feedback mechanism by sensing the intracellular levels of cholesterol. SREBPs function as transcription factors, and upon activation, by low levels of cholesterol, they stimulate the expression of genes coding for proteins involved in the synthesis of cholesterol and fatty acids and in the uptake of lipoproteins (Brown and Goldstein 1997). The basic signaling pathway affected by SREBPs has been elucidated in great detail. However, regulation of SREBPs themselves is proven to be very complex. In the last few years, research has brought new insights regarding this regulation and the interaction with other nutrients and hormones that play a role in energy homeostasis. Recent studies also implicated the SREBP pathway to be important in the development of a range of pathological conditions, associated with obesity and the metabolic syndrome, like liver steatosis and hyperlipidemia (Moon et al. 2012). It has also been described that SREBP has a role in several physiological cellular processes not directly related with lipid homeostasis, like cell growth and innate immunity (Jeon and Osborne 2012). As the insight in the SREBP pathway becomes more and more complex, integration of the different aspects of this knowledge is vital. We will describe the SREBP protein and its isoforms, to continue with a description of the current view on the molecular basis of the SREBP pathway, its complex regulation and its physiological function. In this review, we are applying a pathway approach to investigate the function and regulation of the SREBP proteins in lipid-metabolism-related pathways.

\section{SREBP pathway}

The description of the SREBP pathway in this review will especially focus on the role of the SREBP proteins in lipid- 
metabolism-related pathways. A graphical representation of the SREBP pathway (see Fig. 1) can be found on WikiPathways, a platform for community-based curation of biological pathways (Pico et al. 2008; Kelder et al. 2012). This pathway is a mammalian meta-pathway combining data from mouse, rat, and human studies. The description of the SREBP pathway will refer to this pathway representation on WikiPathways. The interactive pathway viewer on WikiPathways enables the user to zoom, pan, and browse to get detailed information on pathway elements in external databases and thereby allowing a more extensive study (Kelder et al. 2012). The pathway can be found at: http://wikipathways.org/index.php/Pathway: WP1982. The specific version we used for this review was: http://wikipathways.org/instance/WP1982_r59430. Various elements of the pathway (gene products, metabolites, interactions, and the pathway as a whole) are linked to literature references using Pubmed IDs. The gene products are among others linked to genomics databases like ENSEMBL (Flicek et al. 2011), Entrez (Maglott et al. 2011) and UniProt (Consortium 2012) and to databases providing information on biological function and the role in diseases, including Gene Ontology (Ashburner et al. 2000) and OMIM (Borate and Baxevanis 2009). The metabolites are linked to metabolite databases like HMDB (Wishart et al. 2013) and ChEBI (de Matos et al. 2010).
The SREBP family

The SREBP family consists of three subtypes: SREBP-1a and SREBP-1c, which are the result of alternative promoter usage and transcription start sites in the SREBF1 gene, and SREBP-2. All three subtypes were identified by cDNA cloning (Yokoyama et al. 1993; Hua et al. 1993). SREBPs are transcription factors that bind to the sterol regulatory element (SRE) (Yokoyama et al. 1993). They are synthesized as endoplasmic reticulum (ER) membrane proteins. The SREBP protein consists of three domains: a N-terminal domain which has approximately 480 amino acids, in the middle a hydrophobic region of 80 amino acids containing two membrane-spanning domains and a C-terminal regulatory domain of 590 amino acids (Brown and Goldstein 1997). They are oriented in a hairpin fashion in the membranes of the ER and the nuclear envelope, in which the $\mathrm{N}$-terminal and $\mathrm{C}$-terminal project into the cytoplasm.

The N-terminal domain is a basic-helix-loop-helix leucine zipper (bHLH-Zip). This domain is the functionally active portion of the SREBP and functions as the transcription factor. The $\mathrm{N}$-terminal domain starts with an acidic domain that clusters acidic residues and functions as a transactivation domain. Deletion of this acidic domain converts SREBP-1 from an activator to an inhibitor of transcription (Sato et al. 1994). The acidic domain is

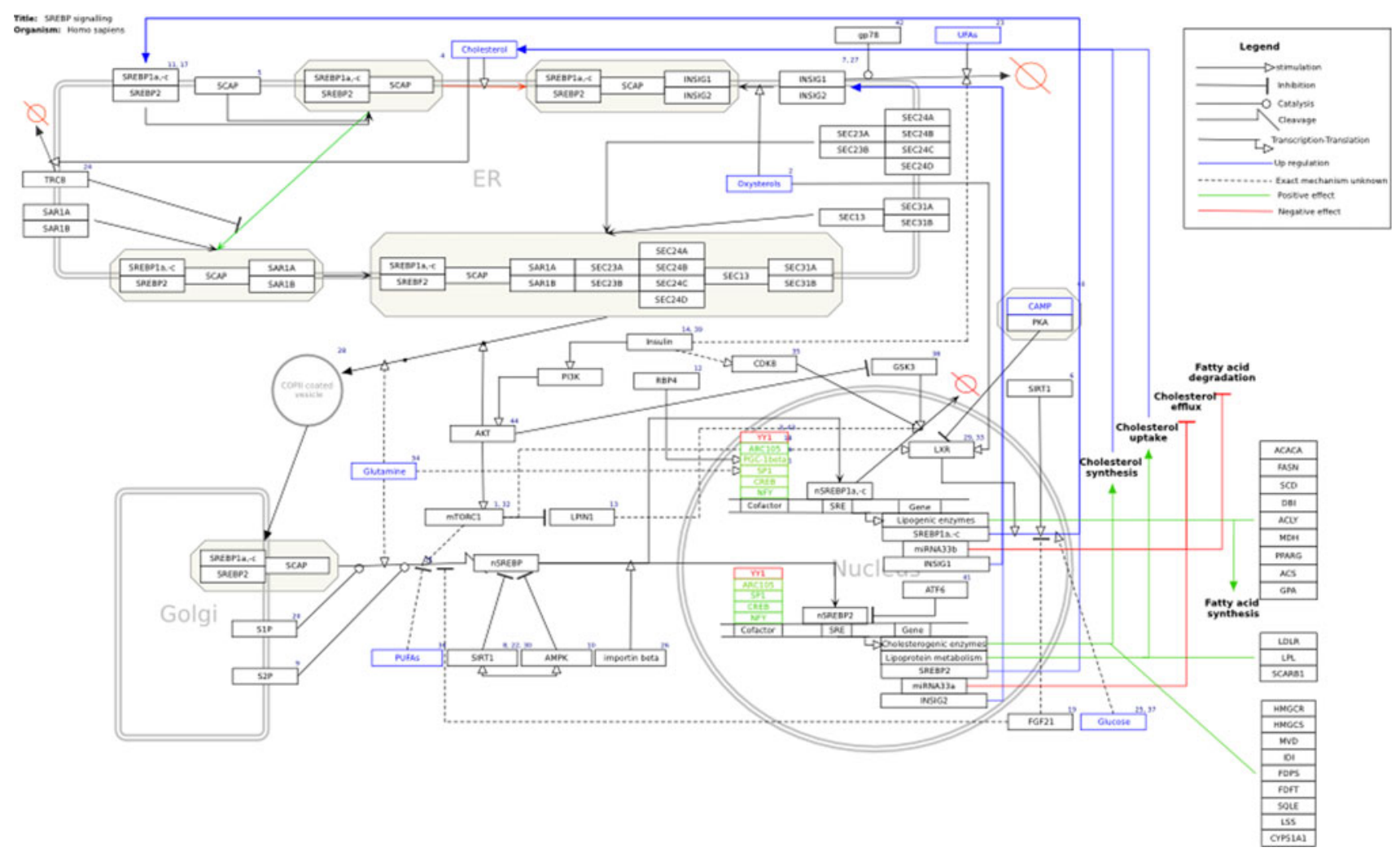

Fig. 1 The SREBP pathway on WikiPathways 


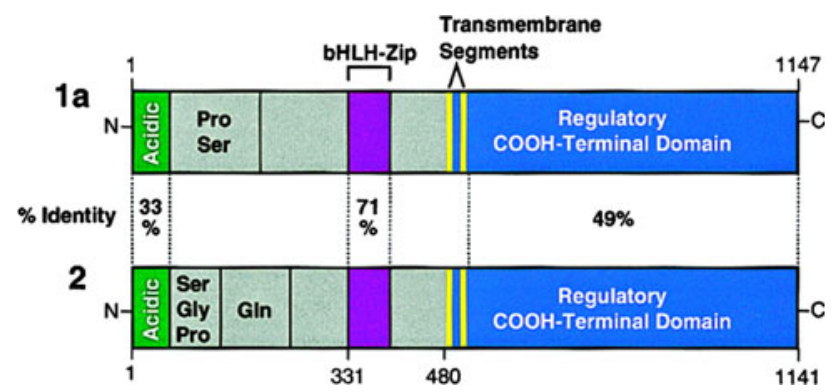

Fig. 2 Protein domains of the SREBP isoforms. The structure of SREBP-1c is highly similar to SREBP-1a; SREBP-1c had a shorter transactivation domain in the N-terminus (Brown and Goldstein 1997)

followed by a region of which the function is unknown. In SREBP-1, this region is proline and serine rich, and in SREBP-2, this region is proline, serine, glutamine, and glycine rich. This region is then followed by the bHLH-Zip domain (Brown and Goldstein 1997). Figure 2 gives an overview of the different protein domains of the SREBP isoforms.

The high similarity among the N-terminal domains of the isoforms of SREBP results in the ability of all isoforms to activate all of the target genes identified so far, but with different efficiencies (Shimano 2001). Given that SREBP$1 \mathrm{c}$ has a shorter transactivation domain, this isoform is a less potent transcription factor than SREBP-1a and SREBP2 (Shimano et al. 1997). Several in vivo studies obtained insight in the distinct roles of the SREBP isoforms. In transgenic mice that overexpress a truncated, active nuclear form of SREBP-2 in liver and adipose tissue, it was shown that SREBP-2 is a relatively selective activator of cholesterol synthesis, as opposed to fatty acid synthesis in these tissues (Horton et al. 1998). SREBP-1 knockout mice showed a significant decrease in mRNA coding for fatty acid synthesis enzymes. There was also a significant increase in cholesterol synthesis, but this was due to activation of SREBP-2, which compensated for the lack of SREBP-1 (Shimano et al. 1999). In general, SREBP-1 is relatively selective for lipogenic genes and SREBP-2 for cholesterogenic genes. This is due to differences among the SREBP isoforms in specificity for SREBP target promoters (Amemiya-Kudo et al. 2002; Pai et al. 1998).

\section{Activation of SREBP}

Since SREBP is bound to the ER membrane, the N-terminal domain must be released before SREBP can activate its target genes in the nucleus. This requires a two-step proteolytic process, which takes place in the Golgi apparatus. Therefore, the SREBP is first transported to the Golgi apparatus. Important for the regulation of the cleavage of SREBP is another ER membrane-embedded protein named SREBP cleavage-activating protein (SCAP). In mice with a
SCAP-deficient liver, no nuclear form of SREBP was found, and they showed an $80 \%$ decrease in basal rates of cholesterol and fatty acid synthesis in the liver (Matsuda et al. 2001). SCAP has an N-terminal domain of 730 amino acids which has eight membrane-spanning regions separated by short hydrophilic loops, which include a sterol-sensing domain (SSD). This domain is similar to the sterol-sensing domain found in other proteins which interact with sterols: 3-hydroxy-3-methylglutaryl-Coenzyme A (HMG CoA) reductase, the Niemann-Pick disease type $\mathrm{C} 1$ protein and Patched (Hua et al. 1996). The C-terminal domain is a hydrophilic region of 546 amino acids containing 4 repeats of a tryptophan-aspartate repeat, WD. Both SREBP-1 and SREBP-2 form a complex with the SCAP protein on the ER membrane by binding of the WD region in SCAP to the C-terminal domain of SREBP. When there are enough sterols present in cells, cholesterol can bind directly to the sterol-sensing domain of SCAP, which then undergoes a conformational change. This conformation favors the binding of SCAP to another ER membrane protein named insulininduced gene (Insig), which blocks translocation of the SREBP-SCAP complex to the Golgi apparatus, where the proteolytic activation takes place (Yang et al. 2002). This can be seen in the upper left corner of the pathway representation. The red arrow indicates the negative effect of cholesterol on SREBP stimulation by stimulating the binding of Insig to the SREBP-SCAP complex. Metabolites, like cholesterol, are indicated in blue boxes in the pathway representation.

There are two Insig isoforms, Insig-1 and Insig-2, which are both polytopic ER membrane proteins. They play an important role in the control of lipid synthesis, not only by binding to the SCAP protein. Insigs also bind to HMG-CoA reductase, which is the rate-limiting enzyme in the synthesis of cholesterol. The binding of Insig to HMG-CoA reductase induces the ubiquitination and proteolysis of this enzyme, whereas binding of Insig to SCAP leads to ER retention (Cao et al. 2007; Sever et al. 2003). The dual function of Insig in cholesterol metabolism is discussed in more detail in (Bengoechea-Alonso and Ericsson 2007). Insig-1 and Insig-2 demonstrate an amino acid identity of $59 \%$ and are both embedded in the ER membrane by six membrane-spanning domains (Yabe et al. 2002). The regulation and the relative stability of the two isoforms differ. Insig-1 is itself a target of SREBP, whereas Insig-2a has been shown to be suppressed by insulin in hepatic cells (Yabe et al. 2003; Yellaturu et al. 2009b). The exact mechanism of the regulation of Insig by insulin remains unclear and is therefore visualized in the WikiPathways pathway using a dashed arrow. The Insig-1 protein is quite unstable and is degraded by the ubiquitinproteasome pathway, whereas insig-2 is a relatively stable protein, which is constitutively expressed at low levels. In transgenic mice that overexpress human Insig-1 in the liver, the levels of all nuclear SREBPs (nSREBPs) were reduced, 
which shows that Insig inhibits SREBP processing (Engelking et al. 2004).

Upon sterol deprivation, the SREBP-SCAP complex dissociates from Insig and moves to the Golgi apparatus, a process that is discussed in more detail in the next section. Insig-1 is then ubiquitinated on lysines 156 and 158 by the membrane-bound ubiquitin ligase gp78. This ubiquitin ligase has a high affinity for Insig-1, and degradation of Insig-1 in a cholesterol-rich environment is probably prevented by binding competition between gp78 and SCAP (Lee et al. 2006). Insig-1 is subsequently degraded in proteasomes, providing a positive feedback mechanism on the activation of SREBP. nSREBPs activate the genes for cholesterol synthesis and uptake and stimulate the production of Insig-1. This upregulation can be seen in the pathway on the right in blue arrows. The new cholesterol and Insig-1 bind the SREBP-SCAP complex and the complex remains in the ER (Gong et al. 2006).

The cholesterol regulatory system is controlled not only by its end product cholesterol but also by oxysterols. Oxysterols are derivatives of cholesterol which have extra keto- or hydroxyl groups. Oxysterols were proven to regulate the interaction of SCAP and Insig, but they do so by a different mechanism than cholesterol. Cholesterol binds to SCAP, while oxysterols bind to Insigs. This induces SCAP to bind to Insig, which inhibits the movement of the SREBP-SCAP complex to the Golgi apparatus (Radhakrishnan et al. 2007). Oxysterols are also ligands of the nuclear liver $X$ receptors (LXRs), which also play an important role in the cholesterol synthesis. Upon activation by oxysterols, LXR forms a heterodimer with the retinoid $X$ receptors (RXRs) which binds to the LXR response element (LXRE) on target genes. An LXRE has been found in the proximal promoter region of the rat cytochrome P450 7A1 (CYP7A1) gene, which codes for an enzyme responsible for the rate-limiting step in the conversion of cholesterol to bile acids (Lehmann et al. 1997). However, in the human gene promotor of CYP7A1, the LXRE appears to be not conserved. In addition, in human primary hepatocyte cultures, it has been shown that activation of the LXR represses CYP7A1 expression, indicating a speciesspecific difference in the regulation of cholesterol homeostasis (Goodwin et al. 2003). In addition, LXRs have been implicated in the upregulation of genes involved in efflux of cholesterol from the cell, as ATP-binding cassette A1 (ABCA1). LXR/RXR can also bind the SREBP-1c promoter and induce SREBP-1 activation of fatty acid synthesis (Schultz et al. 2000).

\section{ER to Golgi transport}

If there are not enough sterols present in the cell, the SREBP-SCAP complex moves to the Golgi apparatus through COPII-coated vesicles. The sorting of the complex in a COPII vesicle is depending on an amino acid sequence in the SCAP protein. SCAP has a long loop, which projects into the cytoplasm between the membrane-spanning helices 6 and 7. In this loop, the hexapeptide MELADL is found, which is required for the binding of the COPII proteins Sec23 and Sec24 to the SREBP-SCAP complex. Clustering of the SREBP-SCAP complex into a COPII vesicle is initiated by Sar1, a small GTPase that binds to the ER membrane GTP dependent. This binding is visualized on WikiPathways by a green arrow, which shows that this is the first step in the cascade toward activation of transcription by SREBPs. The binding of Sar1 initiates the binding of Sec23/24, which then recruits Sec13/31. This heterodimer forms the coat of the vesicle and the vesicle can bud from the ER membrane (Sun et al. 2005). Interaction of SCAP with Insig causes a conformational change in SCAP which inhibits the interaction of MEDADL with Sec23/24.

An ER membrane protein named ring finger protein 139, also called TRC8, shown in the upper right corner on WikiPathways, was identified as a regulator in the SREBP pathway. The protein contains a sterol-sensing domain (SSD) and a RING finger motif, which encodes for an E3 ubiquitin ligase. It is shown that the overexpressing of TRC8 inhibits SREBP-2 processing. TRC8 is capable of binding both SREBP-2 and SCAP and a TRC8-SREBPSCAP complex is formed. This inhibits the binding of SCAP to Sec23/24 and blocks transport of the SREBPSCAP to the Golgi apparatus. The TRC8 protein in itself is highly unstable because of self-ubiquitination, which leads to degradation. When cells were cultured with a lipoprotein-deficient serum, the TRC8 protein became stable (Irisawa et al. 2009). It is thus likely that when the SSD senses a decline in lipoprotein, it will downregulate the E3 ligase activity. It could provide a brake on the SREBP processing in conditions of sterol depletion, preventing too much processing of SREBP (Sato 2010).

\section{Proteolytic cleavage}

After fusion of the COPII vesicle with the Golgi apparatus, the N-terminal of the SREBPs is released by intramembrane proteolysis. The processing of SREBP-nSREBP is shown in the bottom left corner on WikiPathways. The process is executed by two proteases, membrane-bound transcription factor peptidase site 1 , or Site-1 protease (S1P), and Site-2 protease (S2P). The process is initiated when S1P, a membrane-bound serine protease, cleaves the leucine-serine bond in the sequence RSVLS within the luminal loop of SREBP (Duncan et al. 1997). This separates the two membrane-spanning segments. The next step is cleavage by $\mathrm{S} 2 \mathrm{P}$, which hydrolyzes a leucine-cysteine 
bond in the sequence DRSRILLC. This sequence lies within the N-terminal membrane-spanning domain, and cleavage occurs in three residues in this domain (Duncan et al. 1998). The result is that the N-terminal domain is released from the SREBP and functions as an active nSREBP, which migrates to the nucleus to activate target genes (Brown and Goldstein 1999). It has been proposed that the cleavage of $\mathrm{S} 1 \mathrm{P}$ is required for the cleavage of $\mathrm{S} 2 \mathrm{P}$, because the separation of SREBP into two halves causes a conformational change in the first membranespanning domain which allows $\mathrm{S} 2 \mathrm{P}$ to be exposed to its target sequence, thus favoring the cleavage of S2P (Ye et al. 2000). In addition, it has been demonstrated that caspase 3 , a cysteine protease that is involved in the induction of apoptosis, releases mature SREBP from the ER membrane, probably in a sterol-independent manner (Higgins and Ioannou 2001).

\section{SREBP target}

The nSREBPs released during the cleavage reaction travel into the nucleus. This nuclear transport is mediated by karyopherin (importin) beta, which interacts with the bHLH-Zip motif (Nagoshi et al. 1999). Important genes involved in lipid metabolism that are activated by SREBP are listed individually on WikiPathways. Besides activating these target genes, SREBPs also induce transcription of the SREBP gene itself, which contains a SRE, and thus stimulate production of new SREBPs and provide a positive feedback loop. Although SREBPs mainly activate target genes, genes with a SRE sequence have been reported which are repressed by SREBPs. These genes are, for example, microsomal triglyceride transfer protein (MTTP) (Sato et al. 1999) and caveolin (Bist et al. 1997). Since SREBP is active in cases of cholesterol depletion, it is likely that SREBPs repress these genes, which are involved in the efflux of cholesterol and the secretion of lipoproteins (Shimano 2001). The inhibition of genes by SREBP could be due to an indirect effect, namely through activation of repressors. For example, in human myotubes, it has been shown that the transcriptional repressor genes BHLHB2 and BHLHB3 are SREBP-1 target genes, negatively regulating skeletal muscle development (Lecomte et al. 2010).

Activation of the target genes by SREBP requires several cofactors. Usually, nuclear transcription factor $\mathrm{Y}$ (NF$\mathrm{Y})$, Sp1 transcription factor, and CREB-binding protein (CBP) act as cofactors for SREBP. Binding sites for these factors are often found in the SREBP target gene promoters and they are involved in the assembly of the transcription machinery (Bennett and Osborne 2000). The activator recruited-cofactor (ARC)-mediated co-activator complex, a large complex that associates with RNA polymerase II, has also been found to interact with SREBPs. They have been shown to use ARC105 to activate target genes (Yang et al. 2006). The peroxisome proliferator-activated receptor- $\gamma$ coactivator-1 (PGC-1) family functions as important regulators of lipid metabolism. PCG-1 $\beta$ has been found to interact with SREBPs and works as a transcriptional coactivator in the transcription of lipogenic genes (Lin et al. 2005).

Another transcription factor named the YY1 transcription factor seems to be negatively involved in the regulation of SREBP target gene activation. It is shown that the promoters of the HMG-CoA synthase, farnesyl diphosphate (FPP) synthase, and the low-density lipoprotein (LDL) receptor contain YY1 binding sites. YY1 seems to repress SREBP activation by the displacement of NP-Y from the promoter (Ericsson et al. 1999). Other studies suggest YY1 acts by inhibiting the interaction between Sp1 and SREBP (Bennett et al. 1999). The physiological role of YY1, however, is yet to be identified. On WikiPathways, the cofactors are drawn on a cofactor-binding site in the promoter of the target genes. The green colored boxes show activators, whereas the red colored boxes represent repressors.

Interestingly, the SREBF-1 and SREBF-2 gene loci contain, respectively, miR33b in intron 17 and miR33a in intron 16. The mature microRNAs differ in only two nucleotides, but are thought to have a largely overlapping target gene set (Davalos et al. 2011; Rottiers and Naar 2012). These microRNAs appear to work synergistically with SREBP in increasing fatty acid synthesis and cholesterol synthesis and uptake (Rayner et al. 2010; Horie et al. 2010; Gerin et al. 2010). Interestingly, rodents lack the miR33b gene in the SREBF-1 gene (Rayner et al. 2010). Both miR33a and miRNA33b seem to inhibit the expression of genes involved in fatty acid degradation, e.g., carnitine $O$-octanoyltransferase (CROT), and genes that negatively regulate fat production, e.g., insulin receptor substrate 2 (IRS2) (Rottiers and Naar 2012). In addition, they also repress expression of ATP-binding cassette transporter A1 (ABCA1), which normally promotes the efflux of cholesterol from cells to apolipoprotein A1 (APOA1), leading to high-density lipoprotein (HDL) formation (Horie et al. 2010).

\section{Regulation of the SREBP pathway}

Expression and processing of the isoforms of SREBP in vivo was found to be very complex. The SREBP pathway is not just regulated on cell level by the intracellular level of cholesterol, but it can be affected by the nutritional and hormonal status of the body as a whole.

Several studies provided a link between insulin, glucose, and SREBPs. It is known that glucose and insulin stimulate 
fatty acid synthesis through activation of hepatic lipogenic genes. It has been recognized the PI3K/AKT pathway plays an important role in the regulation of SREBP by insulin. A range of studies has been done on exploring the effect of the PI3K/AKT pathway on SREBP, and effects on transcription, activity, processing, and stability have been found (Krycer et al. 2010). A possible mechanism is that insulin increases the migration of the SREBP-SCAP complex from ER to Golgi. Insulin stimulates Akt/PKB-dependent phosphorylation of serine and threonine residues of SREBP-1c. This leads to an increased affinity of the SREBP-SCAP complex for de COPII proteins, Sar1 and Sec23/24, and a decreased affinity for Insig, which retains the SREBPSCAP complex in the ER membrane (Yellaturu et al. 2009a). It has also been shown that insulin enhances processing of SREBP-1c in hepatic cells by stimulation of the degradation of Insig-2a mRNA, reducing Insig-2a protein levels (Yellaturu et al. 2009b). The PI3K/AKT pathway inhibits glycogen synthase kinase 3 (GSK3) through phosphorylation. It has been proposed that this diminishes degradation of mature SREBP-1, since GSK3 has been shown to promote ubiquitination and proteasomal degradation of SREBP-1 through a phosphorylation cascade; GSK3 phosphorylates SREBP-1 at Ser-434, whereby it increases its own affinity for Ser-430 and Thr-426 in SREBP-1, leading to GSK-3-dependent phosphorylation of these sites and a binding site for the ubiquitin ligase Fbw7 (Bengoechea-Alonso and Ericsson 2009). One of the major downstream regulators of the PI3K/AKT pathway is the mammalian target of rapamycin (mTOR). In the past, it has been shown that the mTOR complex-1 (mTORC1) positively regulates the processing of SREBP-1. It was thought this activation was mediated by the ribosomal protein $\mathrm{S} 6$ kinase (RPS6K2), which is phosphorylated by mTORC1 (Duvel et al. 2010). It has recently been shown that insulinmediated stimulation of SREBP-1c processing required mTOR, studied in a hepatic system in which the effect of insulin on SREBP-1c processing could be dissected from the effect of insulin on SREBP-1c transcription, described below. This stimulation of SREBP processing by insulin could be inhibited by using an inhibitor of $\mathrm{p} 70$ ribosomal $\mathrm{S} 6 \mathrm{~K}$, leading to an increase in nSREBP-1c, which was more likely due to an increased production of nSREBP-1c then decreased degradation. The mechanisms by which S6K can lead to increase in nSREBP-1c require further investigation (Owen et al. 2012; Quinn and Birnbaum 2012).

In addition, it has been suggested that the regulation of SREBP-1 is achieved by the regulation of the nuclear entry of phosphatidate phosphatase lipin 1 by mTORC1. Lipins are involved in triacylglycerol biosynthesis and have a second function as transcriptional co-activators. Lipins are sequestered in the cytosol in a hyper-phosphorylated state, and phosphorylation is induced by mTORC1. Loss of
mTORC1-mediated lipin 1 phosphorylation promotes the nuclear entry of lipin 1, and this promotes downregulation of nSREBP, of which the exact mechanism is unknown (Peterson et al. 2011).

Also, insulin can increase basal transcription of the SREBP-1c gene. The liver $\mathrm{X}$ receptor has been reported to have a central role in this insulin-mediated activation of SREBP-1c transcription. In the mouse promoter of SREBP-1c, two LXR elements have been found. In rat primary hepatocytes, it was shown that disruption of both LXREs blunts the effect of insulin on transcription of SREBP-1c (Chen et al. 2004). In contrast, another study did not find a major involvement of the LXREs in the response to insulin, but insulin requires the presence of SRE in the SREBF-1 promoter and enhanced the binding of SREBP-1 to its own promoter. However, it should be noticed that this study made use of a different system based on HEK293 cells (Dif et al. 2006). cAMP, which can be activated by glucagon, and the cAMP-dependent kinase, protein kinase A (PKA) have been shown to suppress SREBP-1c transcription by phosphorylation of LXR, which inhibits the DNA binding activity by inhibiting LXR/RXR dimerization, decreases recruitment of a coactivator, and enhances the recruitment of a corepressor (Yamamoto et al. 2007). In addition, it has been shown in HepG2 cells that PKA can phosphorylate SREBP-1a at Ser338, which reduces DNA binding of SREBP-1c (Lu and Shyy 2006). These results indicate a role for the cAMP/PKA pathway in mediating SREBP-1 and hepatic lipogenesis.

It has been shown that the increase in SREBP-1 expression stimulated by insulin can be inhibited by wortmannin and rapamycin, indicating the PI3K-mTORC1 pathway is involved. In contrast to the stimulation of SREBP-1c processing by insulin, the increase in SREBP-1 expression by insulin could not be blocked by inhibiting S6K. This suggests that the regulation of SREBP-1c by insulin bifurcates downstream of mTORC1, with one arm controlling the processing of SREBP-1c and the other the gene expression (Owen et al. 2012; Quinn and Birnbaum 2012). Furthermore, it has been shown that upstream of this in the liver, by using liver-specific rictor knockout mice, insulin stimulates mTOR complex-2 (mTORC2), which phosphorylated Akt at serine 473, leading to SREBP-1c activation (Hagiwara et al. 2012). Other studies showed that a glucose-dependent increase in SREBP-1c protein, shown in the lower right corner of the pathway, was due to an increase in SREBP-1 mRNA, suggesting that glucose regulates the expression of SREBP-1c at transcriptional level (Hasty et al. 2000). In a human renal proximal tubular cell line, it was shown the glucose-dependent activation of SREBP was potentially mediated through the PI3K/AKT pathway (Hao et al. 2011). SREBP-2 levels remained unchanged when treated with insulin and glucose in the 
liver. That insulin only stimulates hepatic SREBP-1, and not SREBP-2, matches the fact that insulin and SREBP-1 have both been shown to induce lipogenesis. However, in the brain, it has been shown that in insulin-deficient diabetic mice, there is a reduction in the expression of SREBP-2, suggesting that in the brain, insulin upregulates SREBP-2 expression (Suzuki et al. 2010). A complete picture of the regulation of SREBP by insulin and glucose requires additional studies. In addition, cyclin-dependent kinase 8 (CDK8) and its regulatory partner cyclin $\mathrm{C}$ $(\mathrm{CycC})$, which are part of the coactivator mediator complexes in mammalian cells, have been identified as regulators of de novo lipogenesis in Drosophila. Site-specific phosphorylation of nuclear SREBP-1c by CDK8 results in an enhanced ubiquitination and degradation of nSREBP1c. Insulin and feeding decreased the levels of CDK2 and CycC and enhanced the levels SREBP-1c, indicating CDK8-CycC acts downstream of insulin in the regulation of de novo lipogenesis (Zhao et al. 2012).

A crosstalk between SREBP and carbohydrate responsive element-binding protein (ChREBP) has been found. These transcription factors appear to work synergistically to regulate glycolytic and lipogenic gene expression. The phosphorylation of glucose to glucose-6-phosphate by hepatic glucokinase (GK) was found to be essential in the induction of glycolytic and lipogenic genes (Dentin et al. 2004). SREs have been found in the GK promoter, which is an indication that SREBP can activate GK expression after activation by insulin. In the presence of high glucose, xylulose 5-phosphate (X5P) can be formed, which can activate protein phosphatase 2A (PP2A). This phosphatase can dephosphorylate ChREBP, leading to nuclear translocation of this transcription factor, where it binds to carbohydrate response element (ChRE) in the promoter of glycolytic and lipogenic genes. In addition, SREBP-1c can stimulate glycolytic and lipogenic gene transcription after stimulation by insulin. Thus, in the presence of high glucose and insulin, ChREBP and SREBP can work synergistically to activate glycolytic and lipogenic genes (Dentin et al. 2005).

Activating transcription factor-6 (ATF6) has also been found to interact with SREBP-2. ATF6 is also an ER membrane-bound transcription factor, which upon stimulation is translocated from ER to Golgi, where proteolytic cleavage by S1P and S2P occurs (Chen et al. 2002). ATF6 is stimulated by the accumulation of misfolded or unfolded proteins and this ER stress could be caused by glucose deprivation. The cleaved ATF6 translocates to the nucleus and binds to nSREBP-2 bound to target genes promoters. The nuclear ATF6 recruits histone deacetylase 1 (HDAC1), which downregulates SREBP-2 gene expression. The physiological relevance could be that when glucose is depleted, lipogenesis and cholesterogenesis are downregulated to save energy (Zeng et al. 2004).
Alternative regulators of the SREBP pathway are polyunsaturated fatty acids (PUFAs), another example of how diet influences the activation of SREBP. PUFAs have been known as negative regulators of hepatic lipogenesis and have an inhibitory effect on the SREBP pathway. PUFAs appear to suppress the proteolytic processing of SREBP-1c. Suppression of the proteolytic processing of SREBP in turn leads to a decrease in SREBP-1c transcription through lowering SREBP-1c binding to SRE on its own promoter. The exact molecular mechanism underlying this suppression still remains unknown, which is shown by the dashed arrow in the pathway. PUFAs do not seem to affect the functioning of SREBP-2 (Takeuchi et al. 2010). There are several reports suggesting LXR is involved in transcriptional regulation of SREBPs by PUFA (Ou et al. 2001; Yoshikawa et al. 2002). However, several other studies did not find an involvement of LXR in the regulation by PUFA, which could be due to different study systems being used (Takeuchi et al. 2010; Deng et al. 2002). In addition, it has been shown that unsaturated fatty acids inhibit proteosomal degradation of Insig-1. Membrane proteins of the ER can be degraded by the ubiquitination-proteasome system in a process called ER-associated degradation (ERAD). In this process, valosin-containing protein (VCP) extracts ubiquitinated proteins from the membrane making the proteins accessible for degradation in the proteasome. Another protein, named Ubxd8, recruits VCP to Insig-1. Unsaturated fatty acids (UFAs) appear to block to interaction between Ubxd8 and VCP, thereby inhibiting the extraction of Insig-1 from the membrane (Lee et al. 2008).

Recent findings suggest the amino acid glutamine is also involved the regulation of the gene expression and processing of SREBPs, suggesting another link between amino acid metabolism and lipid metabolism. Glutamine seems to increase mRNA levels of several SREBP targets. Glutamine aids in the gene expression of SREBP-1 by increasing the binding of the transcription factor Sp1 to the SREBP-1a promoter. Glutamine also increases the processing of the SREBP protein, presumably by stimulating the transport of the SREBP-SCAP complex from ER to the Golgi apparatus (Inoue et al. 2011).

The $\mathrm{NAD}^{+}$-dependent deacetylase SIRT1 has been shown to directly deacetylate SREBP-1c, leading to a decreased stability of the protein and a reduced association of SREBP-1c with its target genes (Ponugoti et al. 2010). Furthermore, SIRT1 has been shown to downregulate target gene expression by SREBP-1c in vivo under fasting conditions (Walker et al. 2010). Whereas these studied focuses on the liver, recently, it has been shown that SIRT1 also regulated SREBP-1c expression in skeletal muscle. Interestingly, the effect of SIRT1 on SREBP-1c expression was completely abolished when the LXR response elements in the SREBF-1 promoter were deleted, which 
suggest SIRT1 regulates SREBP-1c expression in muscle by deacetylation of LXR transcription factors (Defour et al. 2012). In addition, AMP-activated protein kinase (AMPK) has been shown to directly phosphorylate SREBP-1c and thereby directly inhibit SREBP-1c processing and translocation to the nucleus in the liver ( $\mathrm{Li}$ et al. 2011b). Interestingly, there is evidence that AMPK and SIRT1 stimulate each other and share targets (Ruderman et al. 2010).

A link has also been found between fibroblast growth factor 21 (FGF21) and SREBP-1c in hepatocytes. FGF21 has been identified as a regulator of energy homeostasis, glucose, and lipid metabolism. However, little is known about the regulation or activity of this FGF. It was found that FGF21 downregulated the transcription of SREBP-1c, but the processing of SREBP-1c to its mature form was also diminished. Interestingly, it was found that SREBP-1c could also inhibit FGF21 expression. Molecular mechanisms and biological relevance of this link remain unclear for the time being (Zhang et al. 2011).

Recently, the role of retinol binding protein 4 (RBP4) in lipogenesis has been explored. In HepG2 cells, human RBP4 induces an increase in mature SREBP-1 and its nuclear translocation, which was also confirmed in an in vivo experiment. In addition, treatment of HepG 2 cells with RBP4 leads to a strong upregulation of the expression and protein levels of PCG-1 $\beta$. This suggests that RBP4 induces SREBP-1 activation through induction of PCG-1 $\beta$, leading to an increase in hepatic lipogenesis (Xia et al. 2013). Earlier, it was already reported that retinoic acid and retinal can synergize with insulin to induce the expression of SREBP-1c in primary rat hepatocytes. This was mediated via the retinoid $X$ receptor. This indicated a role of retinol in regulating hepatic lipogenesis (Li et al. 2011a).

\section{Other roles of SREBP}

The important function of SREBP in lipid metabolism led to these proteins being involved in a variety of pathological conditions related to lipid metabolism, as steatosis and hyperlipidemia (Moon et al. 2012). However, several other functions of SREBP, not directly related to lipid metabolism, have emerged recently. SREBPs have been found to regulate several cellular processes, including autophagy, phagocytosis, membrane biogenesis, immunity, hypoxia, and the cell cycle. SREBP-2 has been found to occupy promoters of genes that are involved in mediating autophagy and knockdown of SREBP-2 decreases autophagosome formation in cholesterol-depleted cells, indicating a role for SREBP-2 in autophagy (Seo et al. 2011). Phagocytosis occurs especially within the phagocytic cells of the innate immune system to engulf exogenous particles. Phagocytosis can promote membrane biogenesis via the activation of SREBP-1a and SREBP-2 (Castoreno et al.
2005). In addition, it has been reported that bacterial poreforming toxins can trigger cleavage and activation of SREBP-1 and SREBP-2, probably through caspase-1, which could aid in membrane repair (Gurcel et al. 2006). Furthermore, it has been found that SREBP-1a can induce expression of the anti-apoptotic gene Api6 when toxin is present, which promotes cell survival (Im and Osborne 2012). In fission yeast, it was found that SREBP homologs stimulated transcription of genes that are involved in adaption to hypoxia in response to low oxygen levels (Hughes et al. 2005). Several reports found SREBP to be involved in cell cycle control. nSREBP-1 appears to be hyperphosphorylated by cyclin-dependent kinase (CDK)1/ Cyclin B during mitosis, which stabilizes nSREBP. Furthermore, inactivation of SREBP-1 arrested the cells in the G1 phase of the cell cycle (Bengoechea-Alonso and Ericsson 2006). In addition, expression of the major CDK inhibitor p21 was found to be induced by SREBP-1 (Inoue et al. 2005). Interestingly, miR33, located in the SREBP gene locus, also appears to be involved in the regulation of the cell cycle. miR33 inhibits CDK6 and cyclin D1 and thus reduces cell cycle progression, with overactivation of miR33 even leading to a cell cycle arrest in the G1 phase (Cirera-Salinas et al. 2012). The roles of SREBP beyond lipid metabolism have been reviewed in more detail in recent reviews (Jeon and Osborne 2012; Shao and Espenshade 2012).

\section{Conclusion}

We previously described how literature review can be used to obtain highly curated pathways for biological processes (Adriaens et al. 2008; Jennen et al. 2010), which can be used for data analysis in PathVisio (van Iersel et al. 2008). The new interactive browsing functionality of WikiPathways now allows the pathways themselves to be used as interactive means to study relevant literature and database information on the reactions and entities involved, their known roles in biology and disease, relevant genetic variation, chemical properties, etcetera. The SREBP pathway on WikiPathways described here is an example that makes full use of this functionality.

The basic pathway of SREBP signaling has been well described. When sterol levels are high, Insig retains the SREBP-SCAP complex within the ER membrane. In case of sterol depletion, the SREBP-SCAP complex interacts with COPII proteins and migrates in COPII vesicles to the Golgi apparatus. In the Golgi apparatus, SREBP is cleaved and active nuclear SREBP is released. This nSREBP migrates to the nucleus to activate target genes involved in lipid metabolism. However, the regulation of the pathway proves to be very complex and there are still many 
unanswered questions, especially regarding target genes and regulation. Increasingly, links are being found between the SREBP pathway and other regulators of lipid, protein, and carbohydrate metabolism and overall energy homeostasis: PUFAs are an example how diet influences the SREBP pathway, the link found between glutamine and SREBP suggests another link between amino acid metabolism and lipid metabolism, the interaction of ATF6 and SREBP-2 could imply that the synthesis of cholesterol is slowed in case of energy stress through SREBP-2 inhibition. Especially important to recognize are the links between insulin, glucose, and SREBP, suggesting an important role for SREBP in the pathology of current diseases, as obesity and the metabolic syndrome. Combining and integrating the growing knowledge on the SREBP pathway is essential, in which biological pathway creation and curation can play a major role.

\section{Conflict of interest None.}

Open Access This article is distributed under the terms of the Creative Commons Attribution License which permits any use, distribution, and reproduction in any medium, provided the original author(s) and the source are credited.

\section{References}

Adriaens ME, Jaillard M, Waagmeester A, Coort SL, Pico AR, Evelo CT (2008) The public road to high-quality curated biological pathways. Drug Discov Today 13(19-20):856-862. doi:10.1016/ j.drudis.2008.06.013

Amemiya-Kudo M, Shimano H, Hasty AH, Yahagi N, Yoshikawa T, Matsuzaka T, Okazaki H, Tamura Y, Iizuka Y, Ohashi K, Osuga J, Harada K, Gotoda T, Sato R, Kimura S, Ishibashi S, Yamada N (2002) Transcriptional activities of nuclear SREBP-1a, -1c, and -2 to different target promoters of lipogenic and cholesterogenic genes. J Lipid Res 43(8):1220-1235

Ashburner M, Ball CA, Blake JA, Botstein D, Butler H, Cherry JM, Davis AP, Dolinski K, Dwight SS, Eppig JT, Harris MA, Hill DP, Issel-Tarver L, Kasarskis A, Lewis S, Matese JC, Richardson JE, Ringwald M, Rubin GM, Sherlock G (2000) Gene ontology: tool for the unification of biology. The Gene Ontology Consortium. Nat Genet 25(1):25-29. doi:10.1038/75556

Bengoechea-Alonso MT, Ericsson J (2006) Cdk1/cyclin B-mediated phosphorylation stabilizes SREBP1 during mitosis. Cell Cycle 5(15):1708-1718

Bengoechea-Alonso MT, Ericsson J (2007) SREBP in signal transduction: cholesterol metabolism and beyond. Curr Opin Cell Biol 19(2):215-222. doi:10.1016/j.ceb.2007.02.004

Bengoechea-Alonso MT, Ericsson J (2009) A phosphorylation cascade controls the degradation of active SREBP1. J Biol Chem 284(9):5885-5895. doi:10.1074/jbc.M807906200

Bennett MK, Osborne TF (2000) Nutrient regulation of gene expression by the sterol regulatory element binding proteins: increased recruitment of gene-specific coregulatory factors and selective hyperacetylation of histone H3 in vivo. Proc Natl Acad Sci USA 97(12):6340-6344

Bennett MK, Ngo TT, Athanikar JN, Rosenfeld JM, Osborne TF (1999) Co-stimulation of promoter for low density lipoprotein receptor gene by sterol regulatory element-binding protein and
Sp1 is specifically disrupted by the yin yang 1 protein. J Biol Chem 274(19):13025-13032

Bist A, Fielding PE, Fielding CJ (1997) Two sterol regulatory element-like sequences mediate up-regulation of caveolin gene transcription in response to low density lipoprotein free cholesterol. Proc Natl Acad Sci USA 94(20):10693-10698

Borate B, Baxevanis AD (2009) Searching online Mendelian inheritance in man (OMIM) for information on genetic loci involved in human disease. Curr Protoc Bioinform Chapter 1:Unit 1 2. doi:10.1002/0471250953.bi0102s27

Brown MS, Goldstein JL (1997) The SREBP pathway: regulation of cholesterol metabolism by proteolysis of a membrane-bound transcription factor. Cell 89(3):331-340

Brown MS, Goldstein JL (1999) A proteolytic pathway that controls the cholesterol content of membranes, cells, and blood. Proc Natl Acad Sci USA 96(20):11041-11048

Cao J, Wang J, Qi W, Miao HH, Ge L, DeBose-Boyd RA, Tang JJ, Li BL, Song BL (2007) Ufd1 is a cofactor of gp78 and plays a key role in cholesterol metabolism by regulating the stability of HMG-CoA reductase. Cell Metab 6(2):115-128. doi:10.1016/ j.cmet.2007.07.002

Castoreno AB, Wang Y, Stockinger W, Jarzylo LA, Du H, Pagnon JC, Shieh EC, Nohturfft A (2005) Transcriptional regulation of phagocytosis-induced membrane biogenesis by sterol regulatory element binding proteins. Proc Natl Acad Sci USA 102(37): 13129-13134. doi:10.1073/pnas.0506716102

Chen X, Shen J, Prywes R (2002) The luminal domain of ATF6 senses endoplasmic reticulum (ER) stress and causes translocation of ATF6 from the ER to the Golgi. J Biol Chem 277(15): 13045-13052. doi:10.1074/jbc.M110636200

Chen G, Liang G, Ou J, Goldstein JL, Brown MS (2004) Central role for liver $\mathrm{X}$ receptor in insulin-mediated activation of Srebp-1c transcription and stimulation of fatty acid synthesis in liver. Proc Natl Acad Sci USA 101(31):11245-11250. doi:10.1073/pnas. 0404297101

Cirera-Salinas D, Pauta M, Allen RM, Salerno AG, Ramirez CM, Chamorro-Jorganes A, Wanschel AC, Lasuncion MA, MoralesRuiz M, Suarez Y, Baldan A, Esplugues E, Fernandez-Hernando C (2012) Mir-33 regulates cell proliferation and cell cycle progression. Cell Cycle 11(5):922-933. doi:10.4161/cc.11.5.19421

Consortium U (2012) Reorganizing the protein space at the Universal Protein Resource (UniProt). Nucleic Acids Res 40(Database issue):D71-D75. doi:10.1093/nar/gkr981

Davalos A, Goedeke L, Smibert P, Ramirez CM, Warrier NP, Andreo U, Cirera-Salinas D, Rayner K, Suresh U, Pastor-Pareja JC, Esplugues E, Fisher EA, Penalva LO, Moore KJ, Suarez Y, Lai EC, Fernandez-Hernando C (2011) miR-33a/b contribute to the regulation of fatty acid metabolism and insulin signaling. Proc Natl Acad Sci USA 108(22):9232-9237. doi:10.1073/pnas. 1102281108

de Matos P, Alcantara R, Dekker A, Ennis M, Hastings J, Haug K, Spiteri I, Turner S, Steinbeck C (2010) Chemical entities of biological interest: an update. Nucleic Acids Res 38(Database issue):D249-D254. doi:10.1093/nar/gkp886

Defour A, Dessalle K, Castro Perez A, Poyot T, Castells J, Gallot YS, Durand C, Euthine V, Gu Y, Bechet D, Peinnequin A, Lefai E, Freyssenet D (2012) Sirtuin 1 regulates SREBP-1c expression in a LXR-dependent manner in skeletal muscle. PLoS One 7(9):e43490. doi:10.1371/journal.pone.0043490

Deng X, Cagen LM, Wilcox HG, Park EA, Raghow R, Elam MB (2002) Regulation of the rat SREBP-1c promoter in primary rat hepatocytes. Biochem Biophys Res Commun 290(1):256-262. doi:10.1006/bbrc.2001.6148

Dentin R, Pegorier JP, Benhamed F, Foufelle F, Ferre P, Fauveau V, Magnuson MA, Girard J, Postic C (2004) Hepatic glucokinase is required for the synergistic action of ChREBP and SREBP-1c on 
glycolytic and lipogenic gene expression. J Biol Chem 279(19): 20314-20326. doi:10.1074/jbc.M312475200

Dentin R, Girard J, Postic C (2005) Carbohydrate responsive element binding protein (ChREBP) and sterol regulatory element binding protein-1c (SREBP-1c): two key regulators of glucose metabolism and lipid synthesis in liver. Biochimie 87(1):81-86. doi: 10.1016/j.biochi.2004.11.008

Dif N, Euthine V, Gonnet E, Laville M, Vidal H, Lefai E (2006) Insulin activates human sterol-regulatory-element-binding protein-1c (SREBP-1c) promoter through SRE motifs. Biochem J 400(1): 179-188. doi:10.1042/BJ20060499

Duncan EA, Brown MS, Goldstein JL, Sakai J (1997) Cleavage site for sterol-regulated protease localized to a leu-Ser bond in the lumenal loop of sterol regulatory element-binding protein-2. J Biol Chem 272(19):12778-12785

Duncan EA, Dave UP, Sakai J, Goldstein JL, Brown MS (1998) Second-site cleavage in sterol regulatory element-binding protein occurs at transmembrane junction as determined by cysteine panning. J Biol Chem 273(28):17801-17809

Duvel K, Yecies JL, Menon S, Raman P, Lipovsky AI, Souza AL, Triantafellow E, Ma Q, Gorski R, Cleaver S, Vander Heiden MG, MacKeigan JP, Finan PM, Clish CB, Murphy LO, Manning BD (2010) Activation of a metabolic gene regulatory network downstream of mTOR complex 1. Mol Cell 39(2):171-183. doi: 10.1016/j.molcel.2010.06.022

Engelking LJ, Kuriyama H, Hammer RE, Horton JD, Brown MS, Goldstein JL, Liang G (2004) Overexpression of Insig-1 in the livers of transgenic mice inhibits SREBP processing and reduces insulin-stimulated lipogenesis. J Clin Invest 113(8):1168-1175. doi:10.1172/JCI20978

Ericsson J, Usheva A, Edwards PA (1999) YY1 is a negative regulator of transcription of three sterol regulatory element-binding proteinresponsive genes. J Biol Chem 274(20):14508-14513

Flicek P, Amode MR, Barrell D, Beal K, Brent S, Chen Y, Clapham P, Coates G, Fairley S, Fitzgerald S, Gordon L, Hendrix M, Hourlier T, Johnson N, Kahari A, Keefe D, Keenan S, Kinsella R, Kokocinski F, Kulesha E, Larsson P, Longden I, McLaren W, Overduin B, Pritchard B, Riat HS, Rios D, Ritchie GR, Ruffier M, Schuster M, Sobral D, Spudich G, Tang YA, Trevanion S, Vandrovcova J, Vilella AJ, White S, Wilder SP, Zadissa A, Zamora J, Aken BL, Birney E, Cunningham F, Dunham I, Durbin R, Fernandez-Suarez XM, Herrero J, Hubbard TJ, Parker A, Proctor G, Vogel J, Searle SM (2011) Ensembl 2011. Nucleic Acids Res 39(Database issue):D800-D806. doi:10.1093/nar/gkq1064

Gerin I, Clerbaux LA, Haumont O, Lanthier N, Das AK, Burant CF, Leclercq IA, MacDougald OA, Bommer GT (2010) Expression of miR-33 from an SREBP2 intron inhibits cholesterol export and fatty acid oxidation. J Biol Chem 285(44):33652-33661. doi:10.1074/jbc.M110.152090

Gong Y, Lee JN, Lee PC, Goldstein JL, Brown MS, Ye J (2006) Sterol-regulated ubiquitination and degradation of Insig-1 creates a convergent mechanism for feedback control of cholesterol synthesis and uptake. Cell Metab 3(1):15-24. doi:10.1016/ j.cmet.2005.11.014

Goodwin B, Watson MA, Kim H, Miao J, Kemper JK, Kliewer SA (2003) Differential regulation of rat and human CYP7A1 by the nuclear oxysterol receptor liver X receptor-alpha. Mol Endocrinol 17(3):386-394. doi:10.1210/me.2002-0246

Gurcel L, Abrami L, Girardin S, Tschopp J, van der Goot FG (2006) Caspase-1 activation of lipid metabolic pathways in response to bacterial pore-forming toxins promotes cell survival. Cell 126(6):1135-1145. doi:10.1016/j.cell.2006.07.033

Hagiwara A, Cornu M, Cybulski N, Polak P, Betz C, Trapani F, Terracciano L, Heim MH, Ruegg MA, Hall MN (2012) Hepatic mTORC2 activates glycolysis and lipogenesis through Akt, glucokinase, and SREBP1c. Cell Metab 15(5):725-738. doi: 10.1016/j.cmet.2012.03.015

Hao J, Liu S, Zhao S, Liu Q, Lv X, Chen H, Niu Y, Duan H (2011) $\mathrm{PI} 3 \mathrm{~K} /$ Akt pathway mediates high glucose-induced lipogenesis and extracellular matrix accumulation in $\mathrm{HKC}$ cells through regulation of SREBP-1 and TGF-beta1. Histochem Cell Biol 135(2):173-181. doi:10.1007/s00418-011-0777-3

Hasty AH, Shimano H, Yahagi N, Amemiya-Kudo M, Perrey S, Yoshikawa T, Osuga J, Okazaki $\mathrm{H}$, Tamura $\mathrm{Y}$, Iizuka $\mathrm{Y}$, Shionoiri F, Ohashi K, Harada K, Gotoda T, Nagai R, Ishibashi S, Yamada N (2000) Sterol regulatory element-binding protein-1 is regulated by glucose at the transcriptional level. J Biol Chem 275(40):31069-31077. doi:10.1074/jbc.M003335200

Higgins ME, Ioannou YA (2001) Apoptosis-induced release of mature sterol regulatory element-binding proteins activates sterol-responsive genes. J Lipid Res 42(12):1939-1946

Horie T, Ono K, Horiguchi M, Nishi H, Nakamura T, Nagao K, Kinoshita M, Kuwabara Y, Marusawa H, Iwanaga Y, Hasegawa K, Yokode M, Kimura T, Kita T (2010) MicroRNA-33 encoded by an intron of sterol regulatory element-binding protein 2 (Srebp2) regulates HDL in vivo. Proc Natl Acad Sci USA 107(40):17321-17326. doi:10.1073/pnas.1008499107

Horton JD, Shimomura I, Brown MS, Hammer RE, Goldstein JL, Shimano H (1998) Activation of cholesterol synthesis in preference to fatty acid synthesis in liver and adipose tissue of transgenic mice overproducing sterol regulatory element-binding protein-2. J Clin Invest 101(11):2331-2339. doi:10.1172/JCI2961

Hua X, Yokoyama C, Wu J, Briggs MR, Brown MS, Goldstein JL, Wang X (1993) SREBP-2, a second basic-helix-loop-helixleucine zipper protein that stimulates transcription by binding to a sterol regulatory element. Proc Natl Acad Sci USA 90(24): 11603-11607

Hua X, Nohturfft A, Goldstein JL, Brown MS (1996) Sterol resistance in $\mathrm{CHO}$ cells traced to point mutation in SREBP cleavageactivating protein. Cell 87(3):415-426

Hughes AL, Todd BL, Espenshade PJ (2005) SREBP pathway responds to sterols and functions as an oxygen sensor in fission yeast. Cell 120(6):831-842. doi:10.1016/j.cell.2005.01.012

Im SS, Osborne TF (2012) Protection from bacterial-toxin-induced apoptosis in macrophages requires the lipogenic transcription factor sterol regulatory element binding protein 1a. Mol Cell Biol 32(12):2196-2202. doi:10.1128/MCB.06294-11

Inoue $\mathrm{N}$, Shimano $\mathrm{H}$, Nakakuki M, Matsuzaka T, Nakagawa $\mathrm{Y}$, Yamamoto T, Sato R, Takahashi A, Sone H, Yahagi N, Suzuki H, Toyoshima H, Yamada N (2005) Lipid synthetic transcription factor SREBP-1a activates p21WAF1/CIP1, a universal cyclindependent kinase inhibitor. Mol Cell Biol 25(20):8938-8947. doi:10.1128/MCB.25.20.8938-8947.2005

Inoue J, Ito Y, Shimada S, Satoh SI, Sasaki T, Hashidume T, Kamoshida Y, Shimizu M, Sato R (2011) Glutamine stimulates the gene expression and processing of sterol regulatory element binding proteins, thereby increasing the expression of their target genes. FEBS J 278(15):2739-2750. doi:10.1111/j.1742-4658.2011. 08204. $\mathrm{x}$

Irisawa M, Inoue J, Ozawa N, Mori K, Sato R (2009) The sterolsensing endoplasmic reticulum (ER) membrane protein TRC8 hampers ER to Golgi transport of sterol regulatory elementbinding protein-2 (SREBP-2)/SREBP cleavage-activated protein and reduces SREBP-2 cleavage. J Biol Chem 284(42):2899529004. doi:10.1074/jbc.M109.041376

Jennen DG, Gaj S, Giesbertz PJ, van Delft JH, Evelo CT, Kleinjans JC (2010) Biotransformation pathway maps in WikiPathways enable direct visualization of drug metabolism related expression changes. Drug Discov Today 15(19-20):851-858. doi:10.1016/ j.drudis.2010.08.002 
Jeon TI, Osborne TF (2012) SREBPs: metabolic integrators in physiology and metabolism. Trends Endocrinol Metab 23(2): 65-72. doi:10.1016/j.tem.2011.10.004

Kelder T, van Iersel MP, Hanspers K, Kutmon M, Conklin BR, Evelo CT, Pico AR (2012) WikiPathways: building research communities on biological pathways. Nucleic Acids Res 40(Database issue):D1301-D1307. doi:10.1093/nar/gkr1074

Krycer JR, Sharpe LJ, Luu W, Brown AJ (2010) The Akt-SREBP nexus: cell signaling meets lipid metabolism. Trends Endocrinol Metab 21(5):268-276. doi:10.1016/j.tem.2010.01.001

Lecomte V, Meugnier E, Euthine V, Durand C, Freyssenet D, Nemoz G, Rome S, Vidal H, Lefai E (2010) A new role for sterol regulatory element binding protein 1 transcription factors in the regulation of muscle mass and muscle cell differentiation. Mol Cell Biol 30(5):1182-1198. doi:10.1128/MCB.00690-09

Lee JN, Song B, DeBose-Boyd RA, Ye J (2006) Sterol-regulated degradation of Insig-1 mediated by the membrane-bound ubiquitin ligase gp78. J Biol Chem 281(51):39308-39315. doi: 10.1074/jbc.M608999200

Lee JN, Zhang X, Feramisco JD, Gong Y, Ye J (2008) Unsaturated fatty acids inhibit proteasomal degradation of Insig-1 at a postubiquitination step. J Biol Chem 283(48):33772-33783. doi: 10.1074/jbc.M806108200

Lehmann JM, Kliewer SA, Moore LB, Smith-Oliver TA, Oliver BB, Su JL, Sundseth SS, Winegar DA, Blanchard DE, Spencer TA, Willson TM (1997) Activation of the nuclear receptor LXR by oxysterols defines a new hormone response pathway. J Biol Chem 272(6):3137-3140

Li R, Chen W, Li Y, Zhang Y, Chen G (2011a) Retinoids synergized with insulin to induce Srebp-1c expression and activated its promoter via the two liver $\mathrm{X}$ receptor binding sites that mediate insulin action. Biochem Biophys Res Commun 406(2):268-272. doi:10.1016/j.bbrc.2011.02.031

Li Y, Xu S, Mihaylova MM, Zheng B, Hou X, Jiang B, Park O, Luo Z, Lefai E, Shyy JY, Gao B, Wierzbicki M, Verbeuren TJ, Shaw RJ, Cohen RA, Zang M (2011b) AMPK phosphorylates and inhibits SREBP activity to attenuate hepatic steatosis and atherosclerosis in diet-induced insulin-resistant mice. Cell Metab 13(4):376-388. doi:10.1016/j.cmet.2011.03.009

Lin J, Yang R, Tarr PT, Wu PH, Handschin C, Li S, Yang W, Pei L, Uldry M, Tontonoz P, Newgard CB, Spiegelman BM (2005) Hyperlipidemic effects of dietary saturated fats mediated through PGC-1beta coactivation of SREBP. Cell 120(2):261273. doi:10.1016/j.cell.2004.11.043

Lu M, Shyy JY (2006) Sterol regulatory element-binding protein 1 is negatively modulated by PKA phosphorylation. Am J Physiol Cell Physiol 290(6):C1477-C1486. doi:10.1152/ajpcell.00374.2005

Maglott D, Ostell J, Pruitt KD, Tatusova T (2011) Entrez gene: genecentered information at NCBI. Nucleic Acids Res 39(Database issue):D52-D57. doi:10.1093/nar/gkq1237

Matsuda M, Korn BS, Hammer RE, Moon YA, Komuro R, Horton JD, Goldstein JL, Brown MS, Shimomura I (2001) SREBP cleavage-activating protein (SCAP) is required for increased lipid synthesis in liver induced by cholesterol deprivation and insulin elevation. Genes Dev 15(10):1206-1216. doi:10.1101/ gad. 891301

Moon YA, Liang G, Xie X, Frank-Kamenetsky M, Fitzgerald K, Koteliansky V, Brown MS, Goldstein JL, Horton JD (2012) The Scap/SREBP pathway is essential for developing diabetic fatty liver and carbohydrate-induced hypertriglyceridemia in animals. Cell Metab 15(2):240-246. doi:10.1016/j.cmet.2011.12.017

Nagoshi E, Imamoto N, Sato R, Yoneda Y (1999) Nuclear import of sterol regulatory element-binding protein-2, a basic helix-loophelix-leucine zipper (bHLH-Zip)-containing transcription factor, occurs through the direct interaction of importin beta with HLHZip. Mol Biol Cell 10(7):2221-2233
Ou J, Tu H, Shan B, Luk A, DeBose-Boyd RA, Bashmakov Y, Goldstein JL, Brown MS (2001) Unsaturated fatty acids inhibit transcription of the sterol regulatory element-binding protein-1c (SREBP-1c) gene by antagonizing ligand-dependent activation of the LXR. Proc Natl Acad Sci USA 98(11):6027-6032. doi: 10.1073/pnas.111138698

Owen JL, Zhang Y, Bae SH, Farooqi MS, Liang G, Hammer RE, Goldstein JL, Brown MS (2012) Insulin stimulation of SREBP1c processing in transgenic rat hepatocytes requires p70 S6kinase. Proc Natl Acad Sci USA 109(40):16184-16189. doi: 10.1073/pnas. 1213343109

Pai JT, Guryev O, Brown MS, Goldstein JL (1998) Differential stimulation of cholesterol and unsaturated fatty acid biosynthesis in cells expressing individual nuclear sterol regulatory elementbinding proteins. J Biol Chem 273(40):26138-26148

Peterson TR, Sengupta SS, Harris TE, Carmack AE, Kang SA, Balderas E, Guertin DA, Madden KL, Carpenter AE, Finck BN, Sabatini DM (2011) mTOR complex 1 regulates lipin 1 localization to control the SREBP pathway. Cell 146(3):408-420. doi:10.1016/j.cell.2011.06.034

Pico AR, Kelder T, van Iersel MP, Hanspers K, Conklin BR, Evelo C (2008) WikiPathways: pathway editing for the people. PLoS Biol 6(7):e184. doi:10.1371/journal.pbio.0060184

Ponugoti B, Kim DH, Xiao Z, Smith Z, Miao J, Zang M, Wu SY, Chiang CM, Veenstra TD, Kemper JK (2010) SIRT1 deacetylates and inhibits SREBP-1C activity in regulation of hepatic lipid metabolism. J Biol Chem 285(44):33959-33970. doi: 10.1074/jbc.M110.122978

Quinn WJ 3rd, Birnbaum MJ (2012) Distinct mTORC1 pathways for transcription and cleavage of SREBP-1c. Proc Natl Acad Sci USA 109(40):15974-15975. doi:10.1073/pnas.1214113109

Radhakrishnan A, Ikeda Y, Kwon HJ, Brown MS, Goldstein JL (2007) Sterol-regulated transport of SREBPs from endoplasmic reticulum to Golgi: oxysterols block transport by binding to Insig. Proc Natl Acad Sci USA 104(16):6511-6518. doi:10.1073/pnas. 0700899104

Rayner KJ, Suarez Y, Davalos A, Parathath S, Fitzgerald ML, Tamehiro N, Fisher EA, Moore KJ, Fernandez-Hernando C (2010) MiR-33 contributes to the regulation of cholesterol homeostasis. Science 328(5985):1570-1573. doi:10.1126/ science. 1189862

Rottiers V, Naar AM (2012) MicroRNAs in metabolism and metabolic disorders. Nat Rev Mol Cell Biol 13(4):239-250. doi: 10.1038/nrm3313

Ruderman NB, Xu XJ, Nelson L, Cacicedo JM, Saha AK, Lan F, Ido Y (2010) AMPK and SIRT1: a long-standing partnership? Am J Physiol Endocrinol Metab 298(4):E751-E760. doi:10.1152/ ajpendo.00745.2009

Sato R (2010) Sterol metabolism and SREBP activation. Arch Biochem Biophys 501(2):177-181. doi:10.1016/j.abb.2010. 06.004

Sato R, Yang J, Wang X, Evans MJ, Ho YK, Goldstein JL, Brown MS (1994) Assignment of the membrane attachment, DNA binding, and transcriptional activation domains of sterol regulatory element-binding protein-1 (SREBP-1). J Biol Chem 269(25): 17267-17273

Sato R, Miyamoto W, Inoue J, Terada T, Imanaka T, Maeda M (1999) Sterol regulatory element-binding protein negatively regulates microsomal triglyceride transfer protein gene transcription. J Biol Chem 274(35):24714-24720

Schultz JR, Tu H, Luk A, Repa JJ, Medina JC, Li L, Schwendner S, Wang S, Thoolen M, Mangelsdorf DJ, Lustig KD, Shan B (2000) Role of LXRs in control of lipogenesis. Genes Dev 14(22): 2831-2838

Seo YK, Jeon TI, Chong HK, Biesinger J, Xie X, Osborne TF (2011) Genome-wide localization of SREBP-2 in hepatic chromatin 
predicts a role in autophagy. Cell Metab 13(4):367-375. doi: 10.1016/j.cmet.2011.03.005

Sever N, Yang T, Brown MS, Goldstein JL, DeBose-Boyd RA (2003) Accelerated degradation of HMG CoA reductase mediated by binding of insig-1 to its sterol-sensing domain. Mol Cell 11(1):25-33

Shao W, Espenshade PJ (2012) Expanding roles for SREBP in metabolism. Cell Metab 16(4):414-419. doi:10.1016/j.cmet. 2012.09.002

Shimano H (2001) Sterol regulatory element-binding proteins (SREBPs): transcriptional regulators of lipid synthetic genes. Prog Lipid Res 40(6):439-452

Shimano H, Horton JD, Shimomura I, Hammer RE, Brown MS, Goldstein JL (1997) Isoform 1c of sterol regulatory element binding protein is less active than isoform 1a in livers of transgenic mice and in cultured cells. J Clin Invest 99(5):846854. doi:10.1172/JCI119248

Shimano H, Yahagi N, Amemiya-Kudo M, Hasty AH, Osuga J, Tamura Y, Shionoiri F, Iizuka Y, Ohashi K, Harada K, Gotoda T, Ishibashi S, Yamada N (1999) Sterol regulatory elementbinding protein-1 as a key transcription factor for nutritional induction of lipogenic enzyme genes. J Biol Chem 274(50): 35832-35839

Sun LP, Li L, Goldstein JL, Brown MS (2005) Insig required for sterol-mediated inhibition of Scap/SREBP binding to COPII proteins in vitro. J Biol Chem 280(28):26483-26490. doi: 10.1074/jbc.M504041200

Suzuki R, Lee K, Jing E, Biddinger SB, McDonald JG, Montine TJ, Craft S, Kahn CR (2010) Diabetes and insulin in regulation of brain cholesterol metabolism. Cell Metab 12(6):567-579. doi: 10.1016/j.cmet.2010.11.006

Takeuchi Y, Yahagi N, Izumida Y, Nishi M, Kubota M, Teraoka Y, Yamamoto T, Matsuzaka T, Nakagawa Y, Sekiya M, Iizuka Y, Ohashi K, Osuga J, Gotoda T, Ishibashi S, Itaka K, Kataoka K, Nagai R, Yamada N, Kadowaki T, Shimano H (2010) Polyunsaturated fatty acids selectively suppress sterol regulatory element-binding protein-1 through proteolytic processing and autoloop regulatory circuit. J Biol Chem 285(15):11681-11691. doi:10.1074/jbc.M109.096107

van Iersel MP, Kelder T, Pico AR, Hanspers K, Coort S, Conklin BR, Evelo C (2008) Presenting and exploring biological pathways with PathVisio. BMC Bioinform 9:399. doi:10.1186/14712105-9-399

Walker AK, Yang F, Jiang K, Ji JY, Watts JL, Purushotham A, Boss O, Hirsch ML, Ribich S, Smith JJ, Israelian K, Westphal CH, Rodgers JT, Shioda T, Elson SL, Mulligan P, Najafi-Shoushtari H, Black JC, Thakur JK, Kadyk LC, Whetstine JR, Mostoslavsky R, Puigserver P, Li X, Dyson NJ, Hart AC, Naar AM (2010) Conserved role of SIRT1 orthologs in fasting-dependent inhibition of the lipid/cholesterol regulator SREBP. Genes Dev 24(13):1403-1417. doi:10.1101/gad.1901210

Wishart DS, Jewison T, Guo AC, Wilson M, Knox C, Liu Y, Djoumbou Y, Mandal R, Aziat F, Dong E, Bouatra S, Sinelnikov I, Arndt D, Xia J, Liu P, Yallou F, Bjorndahl T, Perez-Pineiro R, Eisner R, Allen F, Neveu V, Greiner R, Scalbert A (2013) HMDB 3.0- The Human Metabolome Database in 2013. Nucleic Acids Res 41(D1):D801-D807. doi:10.1093/nar/ gks 1065

Xia M, Liu Y, Guo H, Wang D, Wang Y, Ling W (2013) Retinol binding protein 4 stimulates hepatic SREBP-1 and increases lipogenesis through PGC-1beta-dependent pathway. Hepatology. doi: $10.1002 /$ hep. 26227

Yabe D, Brown MS, Goldstein JL (2002) Insig-2, a second endoplasmic reticulum protein that binds SCAP and blocks export of sterol regulatory element-binding proteins. Proc Natl
Acad Sci USA 99(20):12753-12758. doi:10.1073/pnas. 162488899

Yabe D, Komuro R, Liang G, Goldstein JL, Brown MS (2003) Liverspecific mRNA for Insig-2 down-regulated by insulin: implications for fatty acid synthesis. Proc Natl Acad Sci USA 100(6):3155-3160. doi:10.1073/pnas.0130116100

Yamamoto T, Shimano H, Inoue N, Nakagawa Y, Matsuzaka T, Takahashi A, Yahagi N, Sone H, Suzuki H, Toyoshima H, Yamada N (2007) Protein kinase A suppresses sterol regulatory element-binding protein-1C expression via phosphorylation of liver X receptor in the liver. J Biol Chem 282(16):11687-11695. doi:10.1074/jbc.M611911200

Yang T, Espenshade PJ, Wright ME, Yabe D, Gong Y, Aebersold R, Goldstein JL, Brown MS (2002) Crucial step in cholesterol homeostasis: sterols promote binding of SCAP to INSIG-1, a membrane protein that facilitates retention of SREBPs in ER. Cell 110(4):489-500

Yang F, Vought BW, Satterlee JS, Walker AK, Jim Sun ZY, Watts JL, DeBeaumont R, Saito RM, Hyberts SG, Yang S, Macol C, Iyer L, Tjian R, van den Heuvel S, Hart AC, Wagner G, Naar AM (2006) An ARC/mediator subunit required for SREBP control of cholesterol and lipid homeostasis. Nature 442(7103): 700-704. doi:10.1038/nature04942

Ye J, Dave UP, Grishin NV, Goldstein JL, Brown MS (2000) Asparagine-proline sequence within membrane-spanning segment of SREBP triggers intramembrane cleavage by site-2 protease. Proc Natl Acad Sci USA 97(10):5123-5128

Yellaturu CR, Deng X, Cagen LM, Wilcox HG, Mansbach CM 2nd, Siddiqi SA, Park EA, Raghow R, Elam MB (2009a) Insulin enhances post-translational processing of nascent SREBP-1c by promoting its phosphorylation and association with COPII vesicles. J Biol Chem 284(12):7518-7532. doi:10.1074/jbc. M805746200

Yellaturu CR, Deng X, Park EA, Raghow R, Elam MB (2009b) Insulin enhances the biogenesis of nuclear sterol regulatory element-binding protein (SREBP)-1c by posttranscriptional down-regulation of Insig-2A and its dissociation from SREBP cleavage-activating protein (SCAP).SREBP-1c complex. J Biol Chem 284(46):31726-31734. doi:10.1074/jbc.M109.050914

Yokoyama C, Wang X, Briggs MR, Admon A, Wu J, Hua X, Goldstein JL, Brown MS (1993) SREBP-1, a basic-helix-loophelix-leucine zipper protein that controls transcription of the low density lipoprotein receptor gene. Cell 75(1):187-197

Yoshikawa T, Shimano H, Yahagi N, Ide T, Amemiya-Kudo M, Matsuzaka T, Nakakuki M, Tomita S, Okazaki H, Tamura Y, Iizuka Y, Ohashi K, Takahashi A, Sone H, Osuga Ji J, Gotoda T, Ishibashi S, Yamada N (2002) Polyunsaturated fatty acids suppress sterol regulatory element-binding protein 1c promoter activity by inhibition of liver X receptor (LXR) binding to LXR response elements. J Biol Chem 277(3):1705-1711. doi: 10.1074/jbc.M105711200

Zeng L, Lu M, Mori K, Luo S, Lee AS, Zhu Y, Shyy JY (2004) ATF6 modulates SREBP2-mediated lipogenesis. EMBO J 23(4):950-958. doi:10.1038/sj.emboj.7600106

Zhang Y, Lei T, Huang JF, Wang SB, Zhou LL, Yang ZQ, Chen XD (2011) The link between fibroblast growth factor 21 and sterol regulatory element binding protein $1 \mathrm{c}$ during lipogenesis in hepatocytes. Mol Cell Endocrinol 342(1-2):41-47. doi:10.1016/ j.mce.2011.05.003

Zhao X, Feng D, Wang Q, Abdulla A, Xie XJ, Zhou J, Sun Y, Yang ES, Liu LP, Vaitheesvaran B, Bridges L, Kurland IJ, Strich R, Ni JQ, Wang C, Ericsson J, Pessin JE, Ji JY, Yang F (2012) Regulation of lipogenesis by cyclin-dependent kinase 8-mediated control of SREBP-1. J Clin Invest 122(7):2417-2427. doi: 10.1172/JCI61462 